\author{
ANNA BEDNARCZYK \\ 0000-0003-2761-8647 \\ Uniwersytet Łódzki \\ Instytut Rusycystyki \\ Zakład Przekładu i Dydaktyki \\ 91-404 Łódź \\ ul. Pomorska 171/173 \\ anna.bednarczyk@uni.lodz.pl
}

\title{
ПОЭЗИЯ ИГОРЯ СЕВЕРЯНИНА В ПЕРЕВОДЕ НА ПОЛЬСКИЙ ЯЗЫК. ТРАДИЦИЯ И НОВАТОРСТВО (ДВА ПРИМЕРА)
}

\section{IGOR SEVERYANIN'S POETRY IN TRANSLATION INTO POLISH. TRADITION AND INNOVATION (TWO EXAMPLES)}

В статье рассматривается перевод двух стихотворений Игоря Северянина на польский язык. Первая пара стихов (подлинник и перевод) была подвергнута переводческому анализу. Вторая является примером предпероводческого анализа и попыткой выполнить перевод. В центре нашего внимания оказалась проблема сочетания старого и нового, новаторского и традиционного в произведениях поэта (на уровне лексики, образов и формы) и воспроизведение этого сочетания в переводе. Анализ указывает примеры компенсирования переводчиком утраченных элементов исходного текста.

Ключевые слова: Игорь Северянин, новаторство, традиция, перевод.

The article considers the translation of two poems by Igor Severyanin into Polish. In the first case a translational analysis of the source and the target text is offered. The second case is an example of a pre-translation analysis followed by an attempt to make a translation. What is taken into account is the issue of the old combining with the new, the innovative with the traditional in the works of the poet (on the level of vocabulary, imagery and form) and the task of reproducing this fusion in translation. The analysis indicates examples of the translator's compensations for certain lost elements of the source texts.

Keywords: Igor Severyanin, innovation, tradition, translation. 
Mugłbym na nerwah dojżałyh pańen grać, jak na strunah ćenkih, jak włoski. Mogę tak pisać, jak Siewierianin, Mogę tak pisać, jak Majakowskij.

Bruno Jasieński ${ }^{1}$

Когда в 1921 году Бруно Ясенски писал, что он может сочинять и как Игорь Северянин, и как Владимир Маяковский, он поступал, следуя всем положениям эгофутуризма, а также согласно своему преклонению перед авторами футуристических произведений, в том числе перед основоположником эгофутуризма - Северяниным, влияние которого на творчество польского поэта известно. Оно замечалось уже в начале $\mathrm{XX}$ века, о чем пишет, например, Ольга Свенцицка, упоминая колкие замечания других польских поэтов, в том числе Юлиана Тувима, Кароля Ижиковского, Тадеуша Пейпера и других, по поводу творческой манеры Ясенского и его подражания Северянину².

Но, как ни странно, слова Ясенского об умении сочинять «как...» подходят и для дефинирования художественного перевода. «Могу писать, как...», - это слова, которые определяют деятельность переводчика, стремящегося писать как автор подлинника.

Если же говорить о переводчике, которого, согласно мнению Анны Легежинской, считаем вторым автором ${ }^{3}$, мы, несомненно, должны заговорить и о первом сочинителе, так как необходимо ответить на вопрос «как сочинять?». Это, конечно, не ново. Исследователи постоянно стремятся дать ответ на данный вопрос - определить как писал исследуемый ими художник, какие основные черты его творчества? Есть и работы, посвященные творчеству Игоря Северянина ${ }^{4}$. Правда, многие годы оно не особо интересовало исследователей, так как футуристическое начало стихов поэта не вмещалось в рамки

${ }^{1}$ B. Jaśeński, But w butonierce, Stron dzewięćdźeśąt sześćc, Warszawa-Kraków: Nakładem klubu Futurystuw «Katarynka» 1921, [электронный ресурс] https://pl.wikisource.org/wiki/Krytyka_(Jasie\%C5\%84ski) [23.07.2018].

2 O. Święcicka, Autokreacje Brunona Jasieńskiego, «Dwutygodnik.com» 2010, № 8, [электронный ресурс] https://www.dwutygodnik.com/artykul/1396-autokreacje-brunona-jasienskiego.html [14.09.2018].

${ }^{3}$ См., напр.: A. Legeżyńska, Ttumacz i jego kompetencje autorskie. Na materiale powojennych tłumaczeń poezji A. Puszkina, W. Majakowskiego, I. Kryłowa i A. Błoka, Warszawa: PWN 1986, c. 12.

${ }^{4}$ См., напр.: С. Ю. Портнова, Лингвопоэтический аспект оченочных значений в творчестве Игоря Северянина (Игоря Васильевича Лотарева). Диссертация на соискание ученой степени кандидата филологических наук, Москва 2002, [электронный ресурс] http://scicenter.online/ yazyik-russkiy-scicenter/lingvopoeticheskiy-aspekt-otsenochnyih.html [14.09.2018]; С. А. Викторова, Игорь Северянин и поэзия серебряного века (творческие связи и взаимовлияния), [электронный pecypc] http://poet-severyanin.ru/library/severyanin-i-poezia-serebryannogo-veka.html [14.09.2018]. 
соцреалистической литературы. Однако сегодня он снова популярен. Появляются научные труды, анализирующие его тексты, его стихи печатаются и переводятся на другие языки, в том числе и на польский. Хотя, следует отметить, что новые переводы довольно часто появляются не в печати, а в интернет-пространстве.

Итак, вернемся к вопросу «как сочинять?». Как нам кажется, в случае Северянина необходимо учитывать собственную программу поэта, которая предусматривала сочетание нового и старого, введение в стих неожиданных образов, неосемантизмов, неологизмов, нестандартных словосочетаний, а также неполных, ассонансных и диссонансных рифм. Кроме того, следует обратить внимание на известное, характерное исполнение Северяниным стихов, называемых им «поэзами», которые поэт читал как будто бы напевая, внушая читателю ощущение музыкальности. Для переводчика это важные знания, которые помогают в выборе стратегии и методов перевода, так как они определяют одну из формальных доминант трансляции - необходимость сохранить музыкальные характеристики стиха, например, такие как силлабо-тонический стих.

Возвращаясь, однако, к сочетанию новаторства и традиции в произведениях Северянина, отметим, что в его произведениях находим новые, нестандартные стихотворные формы, изобретаемые благодаря использованию и комбинированию разнообразных размеров. Имеются в виду придуманные поэтом: гирлянда триолетов, квадрат квадратов, миньонет, дизель, кензель, сексту и другие. В стихотворениях Северянина замечаются также новые словообразования, неосемантизмы, неожиданные сочетания звуков и нестандартные образы, в том числе соединение «несоединяемых» до сих пор образов, как, например, появившиеся совместно в известнейшей Увертюре (Ананасы в шампанском), с одной стороны, ассоциируемые с роскошью и с изящностью «ананасы» и «шампанское», а с другой - сочетаемые с техникой - «автомобили» и «аэропланы».

Рассуждая о возможности перевода, следует обратить внимание на указанное совмещение в тексте элементов с разной стилистической характеристикой, на то, что несомненно, новаторское творчество Северянина заодно тяготеет и к традиции. Подтверждением сказанному является, хотя бы, использование поэтом классической формы сонета - имеется в виду цикл ста сонетов Медальоны, или же подражание таким твердым стихотворным формам как октава (Октава) и газелла (Газелла) в цикле $B$ настроении чайной розы. Следует также отметить применение известных в поэзии образов или сочетаний красок, используемых, например, символистами, как в случае образа упоминаемой уже чайной розы, фиолетового, жасминового или лилового цветов в их метафорически-символическом значении. 
Важно, что в стихах Северянина стандартное и нестандартное, новое и классическое могут появиться рядом в одном и том же произведении, как в случае неологических изобретений, вмещаемых поэтом в традиционную поэтическую форму. Кстати, благодаря такому подходу к тексту, ведущему к некоторой видовой или стилистической неоднозначности, произведение становится более интересным не только для реципиента первоисточника, но и для переводчика, и, предположительно, для читателя перевода.

В настоящей статье мы сосредоточим внимание именно на сочетании в творчестве русского поэта новаторского и традиционного и попытаемся проследить, каким образом специфика творчества Северянина влияет на выполнение перевода исследуемой поэзии на польский язык. Для этого стоит рассмотреть приемы, используемые переводчиками, осуществляющими переложение стихов, заключающих в себе и новые, и традиционные элементы (лексические, стилистические, формальные). Однако мы не будем сравнивать исследуемых переводов друг с другом, а всего лишь попытаемся рассмотреть конкретные переводческие решения, исходя при этом из доминирующей цели, какой является сохранение интересующих нас явлений. Имея в виду эту цель, присмотримся к двум стихотворениям Северянина и к их польскому переводу.

Первым стихотворением, на котором остановимся, является Кензель, где уже само заглавие является неологизмом. Это особая, созданная поэтом, стихотворная форма, введенная в русскую литературную систему самим Северяниным. Она представляет собой 15-стишие, состоящее из трех частей, каждая из которых насчитывает 5 строк. Первый стих кензели повторяется в стихе как 8 и 15, что создает «зеркальность» формы, а рифмы созданы согласно схеме $a b b b a-c c a c a-a d d d a$. Сравним:

\section{Кензель}

В шумном платье муаровом, в шумном платье муаровом

По аллее олуненной Вы проходите морево...

Ваше платье изысканно, Ваша тальма лазорева,

А дорожка песочная от листвы разузорена-

Точно лапы паучные, точно мех ягуаровый.

Для утонченной женщины ночь всегда новобрачная...

Упоенье любовное Вам судьбой предназначено...

В шумном платье муаровом, в шумном платье муаровом -

Вы такая эстетная, Вы такая изящная...

Но кого же в любовники? и найдется ли пара Вам?

Ножки плэдом закутайте дорогим, ягуаровым,

И, садясь комфортабельно в ландолете бензиновом, 
Жизнь доверьте Вы мальчику, в макинтоше резиновом, И закройте глаза ему Вашим платьем жасминовым -

Шумным платьем муаровым, шумным платьем муаровым!5.

Переводя это произведение, Лиля Хелена Метрыка не только стремилась сохранить все характерные черты формы кензели, что ей удалось, но и воспользовалась сноской, объясняющей происхождение и природу данной стихотворной формы:

* Кензель - стихотворное произведение, созданное Игорем Северяниным. Состоит из 15 строк, которые разделены на три стиха, каждый из которых насчитывает пять строк, где 1 сторка повторяется как 8 и 15. Схема рифмов: abbba-ccaca - addda $^{6}$.

В этом же стихотворении, кроме новаторской формы, встречаются также нестандартные и неологические словообразования: «олуненная аллея», «вы проходите морево», «лапы паучие», «вы такая эстетная». Польский перевод Метрыки воспроизводит их частично. «Частичность» эта заключается прежде всего в компенсировании интересующих нас элементов текста в другом месте и с использованием других лексем. Однако это слова и словосочетания, обладающие такой же стилистической характеристикой, какой они были наделены в подлиннике.

Относительно наблюдаемых в подлиннике и приводимых нами выше определений отметим, что в польском варианте замечается введение других неожиданных словосочетаний или неологизмов. Примером является определенияе «лапы паучие», получившее переводной эквивалент «pająka sieciotwory». В противовес русскому нестандартному словосочетанию появился польский неологизм, построенный на семантической ассоциативности паутиной сети (sieć) и результатов паутинного творчества (twory).

Иногда наблюдаются также пропуски подлинного элемента текста с одновременным введением новаторского явления в другом месте перевода. Примером может послужить пропускаемое переводчицей неологическое словообразование «олуненный» («олуненная аллея») из перовой строки подлинника и введение в третьей строке польского текста неологичного

\footnotetext{
5 А. Северянин, Кензель, [электронный ресурс] https://www.askbooka.ru/stihi/igorseveryanin/kenzel.html [23.07.2018]. Жирный шрифт и курсив мой - А. Б.

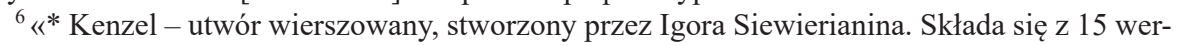
sów podzielonych na 3 strofy pięciowersowe, gdzie 1 wers powtarza się jako 8 i 15. Układ rymów: abbba - ccaca - addda». И. Северянин, Kenzel, перевод L. H. Metryka, [электронный ресурс] http://www.ogrodciszy.pl/viewtopic.php?p=211737\&sid=de8e77c766d4343b687bd5867898a69d [15.09.2018].
} 
слова «rozwzorzona» («Dróżka [...] rozwzorzona»). В данном случае компенсирование касается не семантики, а стилистики текста - сохранения его новаторского характера.

Думается, что этой цели послужило также конкретизирование поэтических образов Северянина, что замечается в замене слов «Жизнь доверьте Вы мальчику в макинтоше резиновым» словами «Życie powierz szoferowi w makintoszu kauczukowym». Новаторство Северянина проявляется здесь во введении в текст некоторой неопределенности, абстрактности, связанной с употреблением слова «мальчик». Данный образ в переводе конкретизирован, и «мальчик» сменен «шофером» - szofer. Кроме того, стоит отметить включение в поэтический текст образа современных технических изобретений. Имеется в виду «резиновый макинтош», замененный переводчицей «каучуковым макинтошем» («w makintoszu kauczukowym»).

В этом месте нам хочется предложить небольшое отклонение в сторону химической технологии. Итак, Чарльз Макинтош в 1823 запатентовал водонепроницательный материал, полученный путем смешения каучука с угольным дегтем, и предложил класть его между двумя слоями ткани. «Трехслойные» плащи, сшитые из материалов, соединенных таким образом, были названы макинтошами. Еще в XIX столетии изобретение Макинтоша подверглось модификации, когда в 1839 г. Чарльз Гудлер придумал вулканизировать каучук, что превращало его в резину, повышая прочность и эластичность нового материала. В XX веке плащи из непромокаемой шерсти стали очень модными.

Итак, оказывается, что «резиновый макинтош» Северянина более реален и менее неожиданный, чем «каучуковый» Метрыки, так как в XX веке, и, следовательно, в 1911 году, когда было написано стихотворение Кензель, непромокаемые плащи производились уже из резины. Таким образом, конкретизирование, к которому пришла польская переводчица, позволяет ввести в текст образ, обладающий большей степенью неожиданности, чем подлинный, и, тем самым, компенсировать некоторые пропуски, наблюдаемые в стилистическом пласте стихотворения. Отметим здесь хотя бы пропуск неологизма «морево» («вы проходите морево»), который нигде не компенсирован.

Хотя, конечно, следует отметить и случаи стопроцентного воспроизведения Метрыкой северяниновской поэтики, примером чего является пара «Вы такая эстетная» и «Pani taka estetyczna», семантика, стиль и место нахождения которых в тексте полностью отвечают друг другу, внушая реципиенту такие же ассоциации и поэтический образ.

Здесь следует обратить внимание и на значение поэтического образа в стихотворениях Северянина, для составления которого, о чем мы уже говорили, автор соединяет в одном произведении традиционные и нестандартные 
для поэзии элементы, что само по себе следует считать новаторским решением. В Кензели примером первых несомненно являются образы, связанные с роскошной дамой в «В шумном платье муаровом», в «лазоревой тальме», «эстетной» и «изящной», которая садится в «бензиновый ландолет» и закутывает ножки «дорогим ягуаровым пледом», к тому же являющейся настолько «утонченной», что для нее «каждая ночь новобрачная». Конечно, здесь можно заметить и некоторую ироничность поэта - ведь ягуаровым оказывается не только дорогой плед, но и «лапы паучные, словно мех ягуаровый», а для новобрачной ночи нужен любовник.

Стоит упомянуть еще некоторые традиционные, или даже стереотипные образы, связанные с выражением романтического восхищения, как применение лазоревого и жасминового цветов («ваша тальма лазолева», «вашим платьем жасминовым»), а также романтического места действия - «аллея олуненная», с рассматриваемым уже неологизмом. Все это подтверждает характерное для Северянина смешение стилей. Метрыка воссоздает большинство этих образов, иногда даже усиливая их романтический или даже восходящий к романсному характер, как в случае строки: «По аллее олуненной Вы проходите морево...» получившей форму: «Pani stąpa po alei lekko jak po falach morza», или же не очень романтичных слов: «Но кого же в любовники? и найдется ли пара Ban?», которые превратились в более поэтические: «Kogo Pani dziś pokocha? komu niebo dziś otworzy?». В целом перевод Метрыки звучит:

\section{Kenzel}

W szeleszczącej sukni z mory, w szeleszczącej sukni z mory

Pani stąpa po alei lekko jak po falach morza,

Pani suknia jest wytworna, peleryna - lazurowa,

Dróżka piaskiem wysypana i listowiem rozwzorzona -

Jakby futro jaguara czy pająka sieciotwory.

Dla kobiety tak subtelnej każda noc poślubną będzie...

Los przeznaczył Pani życie pełne doznań i uniesień...

W szeleszczącej sukni z mory, w szeleszczącej sukni z mory -

Pani taka estetyczna, tyle wdzięku w sobie niesie...

Kogo Pani dziś pokocha? komu niebo dziś otworzy?

Nóżki okryj pledem, Pani, w jaguara drogie wzory,

I wygodnie siedząc w pięknym landolecie benzynowym,

Życie powierz szoferowi w makintoszu kauczukowym,

Później zakryj jego oczy swoim strojem jaśminowym -

Szeleszczącą suknią z mory, szeleszczącą suknią z mory!..?

${ }^{7}$ I. Siewierianin, Kenzel..., [15.09.2018]. 
Можно констатировать, что независимо от некоторых, указанных нами отклонений, перевод воспроизводит характер произведения Северянина, и, прежде всего, характерное для поэта смешение нового и традиции. Этому способствует приверженность к основным формальным признакам кензели, в том числе и к силлабо-тонической системе стиха, и к общим стилистическим характеристикам творчества Северянина, а также применяемое Метрыкой разнообразное компенсирование пропущенных, наделенных стилистической окраской элементов подлинного текста. Именно поэтому микроотклонения, наблюдаемые в тексте перевода, не влияют на акцептабельность перевода в целом.

Второй пример перевода произведения Северянина - это попытка автора настоящего рассуждения перевести сонет Маргерит из цикла Медальо$H b l$, посвященный французскому писателю и драматургу Виктору Маргериту. Исходный текст приводится ниже:

\footnotetext{
Маргерит

Стыдом и гневом грудь моя горит, Когда себя не видя в мальчуганке, Морализирующие поганки Грязь льют на имя - «Виктор Маргерит».

От гнева и немой заговорит, Когда амфо́ры превратив в лоханки, Бездушье безразличной элегантки Грязнит вино помоями корыт...

Что ж, торжествуйте, хамы-нувориши, Кто подлостью набил дома под крыши, Чей мозг не более, чем камамбер...

«Вселенная в границах. Беспредельна Одна лишь глупость человечья», - дельно Уже давно сказал Густав Флобер.
}

На этот раз избранная поэтом форма, несомненно, традиционная. Зато в ней могут встретиться отнюдь нетрадиционные языковые и поэтические явления. Упоминаемая уже Светлана Портнова обращала внимание на появившиеся в нем неологизм «мальчуганка», новообразование «элегантка», а прежде всего на иронию, выражающуюся, между прочим, в использовании

\footnotetext{
${ }^{8}$ И. Северянин, Маргерит, [элекронный ресурс] https://ru.wikisource.org/wiki/Mapгерит_(Северянин) [23.08.2018].
} 
двух антонимичных пар9. Первой является пара: «амфора» - «лоханка», второй - «вино» и «помои». Кроме того, ирония проявляется и в использовании в заключительной терцине сонета интертекстового вкрапления, а именно слов Виктора Флобера, подчеркивающих аналогичность отношения обоих писателей к обществу, которое только считается культурным:

«Вселенная в границах. Беспредельна

Одна лишь глупость человечья», - дельно

Уже давно сказал Густав Флобер ${ }^{10}$.

Здесь стоит еще раз обратить внимание на сочетание в сонете элементов высокого и низкого стилей, последний из которых не должен появиться в этой традиционной форме.

Переводя данный текст, следует, как и в предыдущем случае, соблюдать именно это смешение нового и старого, стремиться к сохранению формы сонета и к воспроизведению стиля Северянина. Учитывая приемы, использованные Метрыкой, можно, как и она, воспользоваться разными видами компенсирования интересующих нас явлений в переводе, к тому же применяя трансформации поэтических образов, предлагаемые в свое время Виктором Коптиловым (имеется в виду расширение и сужение поэтического образа, замену образа другим, а также его перемещение $)^{11}$. Конечно, в данном случае необходимо также воспроизвести в переводе использованные Северяниным слова Флобера: «Вселенная в границах. Беспредельна / Одна лишь глупость человечья» ${ }^{12}$.

Приступая к переложению текста, мы решили заменить эту цитату существующим на польском языке переводом высказывания французского автора и нашли два возможных толкования интересующих нас слов: «Ziemia ma swoje granice, ale ludzka głupota jest nieograniczona» ${ }^{13}$ и «Ziemia ma granice, ale głupota ludzka jest bezgraniczna» ${ }^{14}$. Однако, соблюдая рифмическую

\footnotetext{
${ }^{9}$ C. Ю. Портнова, Лингвопоэтический аспект оценочных значений в творчестве Игоря Северянина... [14.09.2018].

${ }^{10}$ Там же.

${ }^{11}$ В. В. Коптилов, Трансформация художественного образа в поэтическом переводе, [в:] Теория и критика перевода, ред. Б. А. Ларин, Ленинград: Изд. Ленинградского университета 1962 , с. 34-41.

${ }^{12}$ La terre a des limites, mais la bêtise humaine est infinie, [электронный ресурс] http:// www.linternaute.com/citation/40404/la-terre-a-des-limites--mais-la-betise-humaine-est--gustaveflaubert/ [03.12.2018].

${ }^{13}$ G. Flaubert, [электронный ресурс] https://www.hellozdrowie.pl/artykul-madre-glupierzeczy [23.08.2018].

${ }^{14}$ G. Flaubert, [электронный pecypc] https://www.cytatywbutelce.pl/s/ziemia-granice-aleg\%C5\%82upota ludzka-jest-bezgraniczna-32468 [23.08.2018].
} 
схему сонета, следовало модифицировать найденную цитату и в текст она вошла в форме, позволяющей сохранить рифму $a a b c c b$ в завершающих сонет триолетах, и, соответственно, рифму $a a b$ в последнем из них:

„Glob ziemski kres swój ma - ta myśl jest złota -

Lecz bezgraniczna ludzka jest głupota”,

Już dawno stwierdził to Gustave Flaubert.

В свою очередь, воспроизводя замечаемое в подлиннике смешение стилей, мы довольно часто стремились к усилению эмоциональности образа, как в случае «Морализирующих поганок», превратившихся в «Chór starych kwok», который «o moralności syczy» и к игре слов: «W niemowie mowę zrodzić musi gniew» на месте русского «От гнева и немой заговорит». Данные трансфрмации являются последствием стремления передать и новаторское начало поэтики Северянина, и элегантность формы стиха, и смешение стилей, указанное на примере антонимичных пар, которое в нашем варианте воспроизведены как: «amfory» (амфоры) - «szafliki» (ушаты) и «wino» (вино) - «ротује» (помои).

Завершая настоящие рассуждения, пару слов следует посвятить еще упомянутым Портновой новообразованиям «мальчуганка» и «элегантка». В нашем переводе были использованы соответствующие им на польском языке «chłopczyca» и «elegantka», однако, сегодня эти слова не ощущаются как неологизмы, поэтому эмоциональность высказывания, как нам кажется, снижается как в переводе, так и в подлиннике. Можно констатировать, что разнообразные, указываемые нами эмоциональные усиления, вводимые в целевой вариант текста, могут частично компенсировать «исторические» и эмоциональные потери. Наш польский вариант, выполняемый с учетом допереводческого анализа и следующий итогам анализа перевода Кензели авторства Метрыки, выглядит следующим образом:

\section{Margueritte}

Ze wstydu moje serce gubi rytm,

Gdy rysów swych nie widząc u chłopczycy,

Chór starych kwok o moralności syczy,

Mieszając z błotem imię «Margueritte».

W niemowie mowę zrodzić musi gniew, Gdy zamiast amfor z winem są szafliki, Oziębłość elegantki trunek kisi, Pomyje lejąc, ucztę zmienia w chlew... 
No cóż, świętujcie nuworysze-chamy,

Czyj dom po dach podłością jest wypchany.

A rolę mózgu pełni camembert...

„Glob ziemski kres swój ma - ta myśl jest złota -

Lecz bezgraniczna ludzka jest głupota”,

Już dawno stwierdził to Gustave Flaubert.

На основании анализа всего лишь двух текстов нельзя судить о всем творчестве ни автора подлинника, ни переводчика, нельзя также высказываться о переводческой парадигме, которую следует применять, переводя данные тексты, однако, можно предвидеть переводческие проблемы, которые будут появляться в процессе перевода других текстов данного автора, определить методы, которые поспособствуют адекватному или акцептабельному переводу (что зависит от нашей ориентировки, либо на культуру источника, либо перевода), и, как в нашем случае, указать необходимое для переводчика поэзии Северянина умение балансировать между новаторством и традицией.

Завершая настоящие рассуждения, стоит еще раз обратиться к словам Ясенского относительно написания текста «как кто-то другой». И, так как нас интересовало не подражание, а перевод, можно прийти к выводу, что в противовес эпигонам, подражающим своему кумиру, переводчик является творцом, а его труд - настоящим первостепенным авторским достижением наравне с первоисточником. Особенно тогда, когда он акцептабелен и входит в литературную систему культуры перевода.

И даже, если признать перевод подражанием, то это подражание особого рода, так как, если оно чрезмерно приближается к подлиннику, целевой текст оказывается не плагиатом, а творением бездарного графомана. И, если это так, тогда именно обоснованное отклонение от оригинала, во имя сохранения творческого характера произведения, позволяет рассуждать о настоящем творчестве и об авторских решениях переводчика - второго автора (не подражателя).

Кстати, Ясенски переводил русскую поэзию, в том числе и Маяковского, и Северянина, доказывая таким образом умение писать «как», однако, анализ его переводов нуждается в отдельных исследованиях, точно так же как и перевод его стихотворений. Наши рассуждения предлагаем завершить фрагментом одного из них в нашем переводе:

На тонькой струнькой нерьвоф рваньи

Девиц созьрефших сиграть иа смох бы

Могу писать как Сэвэрианин

Могу писать как Майиакофский. 


\section{References}

Flaubert, Gustave. https:/www.cytatywbutelce.pl/s/ziemia-granice-ale-g\%C5\%82upotaludzka-jestbezgraniczna-32468.

Flaubert, Gustave. https://www.hellozdrowie.pl/artykul-madre-glupie-rzeczy.

Jaśeński, Bruno. But w butonierce, Stron dzewięćdźeśąt sześć. Warszawa-Kraków: Nakładem klubu Futurystuw "Katarynka", 1921. https://pl.wikisource.org/wiki/Krytyka_(Jasie\%C5\%84ski).

Koptilov, Viktor V. Transformatsiya khudozhestvennogo obraza v poeticheskom perevode. In: Teoriya $i$ kritika perevoda, ed. B. A. Larin. Leningrad: Izd. Leningradskogo universiteta, 1962: 34-41.

Legeżyńska, Anna. Ttumacz i jego kompetencje autorskie. Na materiale powojennych thumaczeń poezji A. Puszkina, W. Majakowskiego, I. Kryłowa i A. Błoka. Warszawa: PWN, 1986.

Portnova, Svetlana J. Lingvopoeticheskii aspekt otsenochnykh znachenii $v$ tvorchestve Igorya Severyanina (Igorya Vasilievicha Lotareva). Dissertatsiya na soiskanie uchonoi stepeni kandidata filologicheskikh nauk. Moskva 2002. http:/scicenter.online/yazyik-russkiyscicenter/ lingvopoeticheskiy-aspekt-otsenochnyih.html.

Severyanin, Igor. Kenzel. 1911. https://www.askbooka.ru/stihi/igor-severyanin/kenzel.html.

Severyanin, Igor. Kenzel. transl. L. H. Metryka. http://www.ogrodciszy.pl/viewtopic.php?p=21173 $7 \&$ sid= de8e77c766d4343b687bd5867898a69d.

Severyanin, Igor. Margueritte. https://ru.wikisource.org/wiki/Маргерит_(Северянин).

Święcicka, Olga. "Autokreacje Brunona Jasieńskiego". Dwutygodnik.com, No. 8 (2010). https:// www.dwutygodnik.com/artykul/1396-autokreacje-brunona-jasienskiego.html.

Viktorova, Stepanida A. Igor Severyanin i poeziya serebryannogo veka (tvorcheskie svyazi i vzaimovliyaniya). http://poet-severyanin.ru/library/severyanin-i-poezia-serebryannogo veka.html. 